\title{
Novel index for predicting mortality during the first 24 hours after traumatic brain injury
}

\author{
Hakseung Kim, PhD, ${ }^{1}$ Hack-Jin Lee, MEng, ${ }^{1}$ Young-Tak Kim, MEng, ${ }^{1}$ Yunsik Son, PhD, ${ }^{2}$ \\ Peter Smielewski, PhD, ${ }^{3}$ Marek Czosnyka, PhD, ${ }^{3,4}$ and Dong-Joo Kim, PhD ${ }^{1}$ \\ 'Department of Brain and Cognitive Engineering, Korea University, Seoul; '2Department of Computer Engineering, Dongguk \\ University, Seoul, South Korea; ${ }^{3}$ Division of Neurosurgery, Department of Clinical Neurosciences, University of Cambridge, \\ United Kingdom; and ${ }^{4}$ Institute of Electronic Systems, Warsaw University of Technology, Warsaw, Poland
}

\begin{abstract}
OBJECTIVE Failure of cerebral autoregulation and subsequent hypoperfusion is common during the acute phase of traumatic brain injury $(\mathrm{TBI})$. The cerebrovascular pressure-reactivity index $(\mathrm{PRx})$ indirectly reflects cerebral autoregulation and has been used to derive optimal cerebral perfusion pressure (CPP). This study provides a method for the use of a combination of PRx, CPP, and intracranial pressure (ICP) to better evaluate the extent of cerebral hypoperfusion during the first 24 hours after TBI, allowing for a more accurate prediction of mortality risk.
\end{abstract}

METHODS Continuous ICP and arterial blood pressure (ABP) signals acquired from 295 TBI patients during the first 24 hours after admission were retrospectively analyzed. The CPP at the lowest PRx was determined as the optimal CPP (CPPopt). The duration of a severe hypoperfusion event (dHP) was defined as the cumulative time that the PRx was > 0.2 and the CPP was $<70 \mathrm{~mm} \mathrm{Hg}$ with the addition of intracranial hypertension (ICP > 20 or $>22 \mathrm{~mm} \mathrm{Hg}$ ). The outcome was determined as 6 -month mortality.

RESULTS The cumulative duration of PRx $>0.2$ and CPP $<70 \mathrm{~mm} \mathrm{Hg}$ exhibited a significant association with mortality $(p<0.001)$. When utilized with basic clinical information available during the first 24 hours after admission (i.e., Glasgow Coma Scale score, age, and mean ICP), a dHP > 25 minutes yielded a significant predictive capacity for mortality ( $\mathrm{p}<$ 0.05 , area under the curve $[A \cup C]=0.75$ ). The parameter was particularly predictive of mortality for patients with a mean $\mathrm{ICP}>20$ or $>22 \mathrm{~mm} \mathrm{Hg}$ (AUC $=0.81$ and 0.87 , respectively).

CONCLUSIONS A short duration (25 minutes) of severe hypoperfusion, evaluated as lowered CPP during worsened cerebrovascular reactivity during the 1 st day after TBI, is highly indicative of mortality.

https://thejns.org/doi/abs/10.3171/2018.7.JNS18995

KEYWORDS cerebral autoregulation; cerebral perfusion pressure; cerebrovascular reactivity; neurocritical care; traumatic brain injury

L OWERED cerebral blood flow (CBF) is an immediate consequence of traumatic brain injury (TBI). ${ }^{35}$ The subsequent secondary ischemic insult in the brain is a well-known phenomenon; hence, maintaining an adequate level of $\mathrm{CBF}$ is considered to be one of the primary objectives during the management of TBI. ${ }^{6}$ Normally, the cerebral circulation maintains a relatively constant $\mathrm{CBF}$, despite the fluctuations in cerebral perfusion pres- sure (CPP), through an intrinsic, homeostatic mechanism known as cerebral autoregulation. ${ }^{25}$ However, this mechanism often fails in patients with TBI, especially within the first few days of the incident. ${ }^{12}$ With failed cerebral autoregulation, a change in CPP would result in a passive fluctuation of CBF (i.e., cerebral perfusion becomes directly pressure dependent); hence, the brain becomes highly vulnerable to hypoperfusion and worse outcomes. ${ }^{5,8,15}$ Thus,

ABBREVIATIONS $\mathrm{ABP}=$ arterial blood pressure $\mathrm{AUC}=$ area under the curve; $\mathrm{CBF}=$ cerebral blood flow; $\mathrm{CPP}=$ cerebral perfusion pressure; $\mathrm{CPPopt}=\mathrm{optimal} \mathrm{CPP}$; $\triangle \mathrm{CPP}=$ optimal $\mathrm{CPP}-$ measured $\mathrm{CPP} ; \mathrm{dHP}=$ duration of a severe hypoperfusion event; dHP20 $=\mathrm{dHP}$ with an ICP threshold of $20 \mathrm{~mm} \mathrm{Hg} ; \mathrm{dHP} 22=\mathrm{dHP}$ with an ICP threshold of $22 \mathrm{~mm} \mathrm{Hg}$; GCS = Glasgow Coma Scale; ICP = intracranial pressure; NCCU = neurocritical care unit; PRx = pressure-reactivity index; ROC = receiver operating characteristic; $\mathrm{TBI}=$ traumatic brain injury

SUBMITTED April 12, 2018. ACCEPTED July 31, 2018.

INCLUDE WHEN CITING Published online December 21, 2018; DOI: 10.3171/2018.7.JNS18995. 
the signs of deteriorating cerebral autoregulation and subsequent hypoperfusion in TBI patients, especially within the first few days of injury, should be rigorously investigated.

In practice, the status of cerebral autoregulation can be indirectly assessed by measuring the cerebrovascular pressure reactivity. ${ }^{9}$ Defined as the moving correlation coefficient between arterial blood pressure (ABP) and intracranial pressure (ICP), the pressure-reactivity index (PRx) has been considered as a de facto surrogate measure of cerebral autoregulation. ${ }^{17,30,36}$ Furthermore, in recent years, the PRx has been highlighted for its efficacy in detecting the optimal level of CPP; when plotted against the PRx, a specific point of CPP with the lowest PRx would be identified, which is supposed to be the optimal CPP (CPPopt) with the strongest autoregulatory ability. ${ }^{21,31}$

The CPPopt can provide the means to determine the patient-specific adequate level of CPP and may be useful in the prognosis of TBI and hemorrhagic strokes. ${ }^{13,28}$ However, the PRx, which is the basis of the CPPopt, has an important limitation: the parameter may not function as intended if the intracranial compliance is low. ${ }^{1,26}$ This is problematic because during neurocritical care of TBI patients, the ICP is often aggressively managed. If ICP is maintained below a certain level (e.g., $<10 \mathrm{~mm} \mathrm{Hg}$ ) or if a patient has undergone decompressive craniotomy, ${ }^{1,3,27}$ the intracranial compliance would be relatively high, which could undermine the efficacy of the PRx and CPPopt in the management of TBI.

Recent studies have reported a significant association between CPP < CPPopt and mortality or poor outcomes, ${ }^{14,21,28}$ indicating that the prognostic capacity of CPPopt is due to its ability to identify cerebral hypoperfusion rather than hyperperfusion. Cerebral hypoperfusion can be detrimental, even for a short duration, during the first 24 hours of the TBI. ${ }^{34}$ In this study, we speculated that the extent of hypoperfusion would be reflected by a specifically designed parameter that incorporates the combined status of hypotension, intracranial hypertension, and cerebrovascular reactivity. In addition, this study tested the prognostic capacity of this parameter during the first 24 hours of ICP monitoring.

\section{Methods}

This study investigated the association between the duration of cerebral hypoperfusion and mortality in TBI patients during the first 24 hours of neurocritical care unit (NCCU) admission. Cerebral hypoperfusion events were determined based on the thresholds of ICP, CPP, and the PRx, which are known to be associated with outcome after TBI.,19,29 The duration of cerebral hypoperfusion was defined as the cumulative duration of the events.

\section{Patients}

This study was conducted as a retrospective analysis of a prospectively maintained database cohort, in which high-frequency clinical neuromonitoring data had been archived. The monitoring of brain modalities was conducted as part of the standard NCCU patient care, using an anonymized database of physiological monitoring vari- ables in neurocritical care. Data on age, injury severity, and clinical status at the time of hospital discharge were recorded at the time of monitoring in this database, and no attempts were made to re-access clinical records for additional information. Since all data were extracted from the hospital records and were fully anonymized, no data on patient identifiers were available, and formal patient or proxy consent was not required. The use of collected data was approved by the local research ethics committee. The following inclusion criteria were applied: 1) etiology was strictly TBI and 2) ICP and ABP were continuously measured for 24 hours. All available data met the inclusion criteria. The exclusion criteria were as follows: 1) patients without outcome information ( $\mathrm{n}=13), 2)$ patients whose data had a significant number of signal artifacts $(n=16)$, and 3) patients whose CPPopts could not be calculated (n =1). Consequently, data on 295 TBI patients were retrospectively collected and analyzed. This cohort of patients has also been evaluated in previous studies. ${ }^{2,18,32}$ The institutional ICP/CPP protocol (NCCU: ICP/CPP management algorithm ${ }^{24}$ ) was applied to all patients, aiming for ICP $<$ $20 \mathrm{~mm} \mathrm{Hg}$ and CPP > $60 \mathrm{~mm} \mathrm{Hg}$ via therapeutic interventions (e.g., osmotic agents, induced hypothermia, moderate hyperventilation, vasopressors, intravenous fluids). The severity of injury was not available for investigation; however, based on our experience, patients admitted to the NCCU typically have an Injury Severity Score of 25, both before and during admission. ${ }^{24}$

\section{Data Acquisition}

ABP was monitored from the radial or femoral artery using a standard pressure monitoring kit (Baxter Healthcare, CardioVascular Group). ICP was monitored at the intraparenchymal site (Codman ICP MicroSensor, Codman \& Shurtleff). Monitored signals were sampled at 100 $\mathrm{Hz}$ and converted to a digital signal via an A/D converter (DT9801, Data Translation) for analysis using ICM+ software (Cambridge Enterprise, www.neurosurg.cam.ac.uk/ icmplus). In the preprocessing phase, signal artifacts (e.g., transducer flushing, motion) were manually eliminated. All pressure values (ICP, ABP, and CPP) were obtained from a moving average window with a 10 -second interval to suppress the effects of pulse and respiratory waves.

\section{Determination of a Cerebral Hypoperfusion Event}

In this study, a set of time ranges satisfying certain conditions was defined as a cerebral hypoperfusion event. Theoretically, a decrease in CPP $\left(<70 \mathrm{~mm} \mathrm{Hg}^{29}\right)$ when cerebrovascular reactivity has failed $\left(\mathrm{PRx}>0.2^{19}\right)$ would result in hypoperfusion. In addition, the PRx could lose its efficacy if intracranial compliance is high and/or ICP is lowered..$^{1,26}$ The conventional and recent thresholds of ICP for identifying severe intracranial hypertension are 20 and $22 \mathrm{~mm} \mathrm{Hg}$, respectively. ${ }^{1,3,7}$ The 2 thresholds of ICP were utilized separately to investigate whether such a small difference (i.e., $2 \mathrm{~mm} \mathrm{Hg}$ ) would affect the prognostic capacity of the novel parameter proposed in this study. Due to the management protocol of the institution, an event of ICP $>20 \mathrm{~mm} \mathrm{Hg}$ and CPP $<60 \mathrm{~mm} \mathrm{Hg}$ was quite rare in the data used in this study. Thus, a CPP threshold of 70 

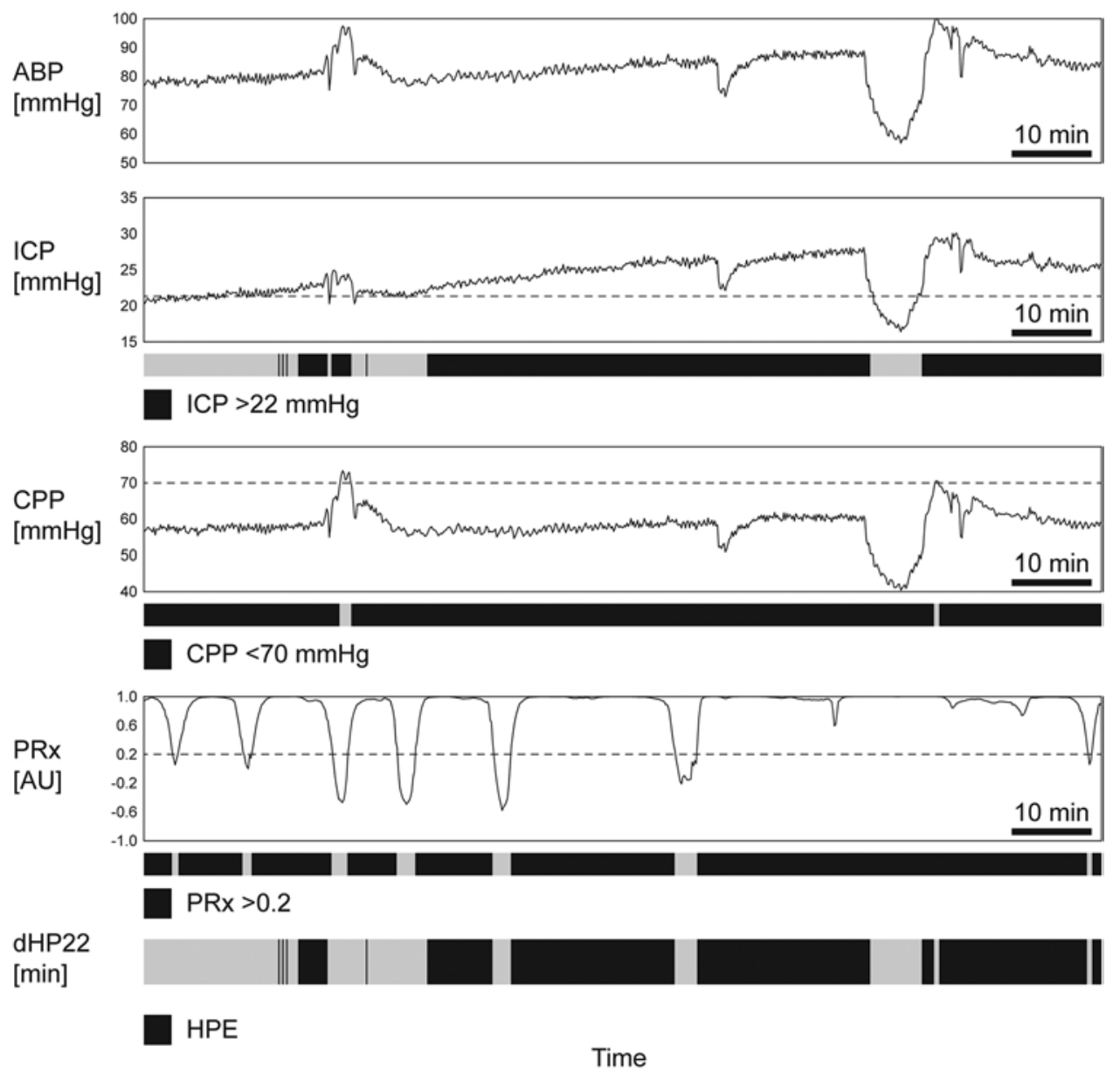

FIG. 1. A graphic representation of dHP derivation. Each shaded area under the time series data denotes the duration of ICP over a certain threshold ( $22 \mathrm{~mm} \mathrm{Hg}$ in this example), CPP $<70 \mathrm{~mm} \mathrm{Hg}$, and PRx $>0.2$. The black area indicates the dHP, which implies an increase in ICP, decrease in CPP, and worsening of PRx all occurring at the same time. dHP22 = duration of the severe hypoperfusion event (PRx $>0.2, \mathrm{CPP}<70 \mathrm{~mm} \mathrm{Hg}$, and ICP $>22 \mathrm{~mm} \mathrm{Hg}) ; \mathrm{HPE}=$ hypoperfusion event.

$\mathrm{mm} \mathrm{Hg}$ was chosen for defining lowered CPP. Accordingly, the following criteria were speculated to better reflect an event of severe hypoperfusion: PRx $>0.2^{19}$ and ICP $>$ $20 \mathrm{~mm} \mathrm{Hg}{ }^{1,3}$ and/or $>22 \mathrm{~mm} \mathrm{Hg}$, ${ }^{7}$ and CPP $<70 \mathrm{~mm} \mathrm{Hg}$. This event is hereafter denoted as dHP (duration of severe hypoperfusion; $\mathrm{dHP} 20=\mathrm{dHP}$ constructed from an ICP threshold of $20 \mathrm{~mm} \mathrm{Hg}$; dHP22 = dHP constructed from an ICP threshold of $22 \mathrm{~mm} \mathrm{Hg}$ ). To minimize the effect of noisy fluctuations in parameters, the conditions were determined as a hypoperfusion event only if they lasted for more than 5 minutes continuously. From the identified hypoperfusion events, the sum of the event duration during a 24-hour recording (i.e., cumulative duration) was calculated. An example of detecting a cerebral hyperperfusion event is shown in Fig. 1.

Additionally, the extent of hypoperfusion measured by CPPopt was defined as the duration of when CPPopt - CPP $(\Delta \mathrm{CPP})>5 \mathrm{~mm} \mathrm{Hg} .{ }^{13}$ The PRx for identifying the CPPopt was determined by the moving Pearson's correlation coefficient, which was calculated using the 10 -second averaged ABP and ICP in a 300 -second window..$^{10} \mathrm{CPPopt}$ was calculated as per the methods provided in a previous study. ${ }^{31}$

\section{Statistical Analysis}

Nonparametric statistical methods were used in this study. The data are expressed as the median and IQR. The Mann-Whitney U-test was performed for continuous parameters, and the chi-square test was used for categorical variables. Receiver operating characteristic (ROC) curve analysis was performed to assess the prognostic capability of the duration of the cerebral hypoperfusion event, and the areas under the ROC curve (AUCs) of the parameters were directly compared using DeLong's method. Bonferroni correction was used to adjust the significance levels in multiple comparisons. ${ }^{11}$ Based on the ROC curve, the detailed prognostic capability of the optimal threshold with the maximum value of Youden's index (J) (sensitivity + specificity -1) was evaluated by the sensitivity, specificity, positive predictive value, negative predictive value, positive likelihood ratio, negative likelihood ratio, accuracy, and net prediction [(sensitivity + specificity)/2]. The prognostic capacities of the utilized parameters were evaluated using the records of all available patients, and patients exhibited a mean ICP $>20 \mathrm{~mm} \mathrm{Hg}^{1,3}$ and/or $>22 \mathrm{~mm} \mathrm{Hg}{ }^{7}$ Multivariate logistic regression models were established for mortality prediction. Covariates of the models con- 
TABLE 1. Baseline characteristics

\begin{tabular}{lccc}
\hline & Survived $(\mathrm{n}=226)$ & Died $(\mathrm{n}=69)$ & $\mathrm{pValue}^{*}$ \\
\hline Age, yrs & $33(21$ to 45$)$ & $44(30$ to 60.75$)$ & $<0.001$ \\
\hline No. of males & $167(73.9)$ & $55(79.7)$ & 0.33 \\
\hline GCS score & $7(4$ to 9$)$ & $5(3$ to 8$)$ & 0.02 \\
\hline Mean values in 24-hr recording & & \\
\hline ABP, $\mathrm{mm} \mathrm{Hg}$ & $89.01(85.54$ to 93.2$)$ & $90.96(85.65$ to 96.54$)$ & 0.10 \\
\hline ICP, $\mathrm{mm} \mathrm{Hg}$ & $17.58(14.8$ to 21.6$)$ & $19.84(14.29$ to 24.97$)$ & 0.10 \\
\hline CPP, $\mathrm{mm} \mathrm{Hg}$ & $70.85(70.15$ to 71.96$)$ & $70.64(69.94$ to 71.31$)$ & 0.09 \\
\hline PRx & $-0.06(-0.23$ to 0.13$)$ & $0(-0.19$ to 0.25$)$ & 0.08 \\
\hline ICP group & & & 0.02 \\
\hline Mean $>22 \mathrm{~mm} \mathrm{Hg}, \mathrm{n}(\%)$ & $50(22.1)$ & $25(36.2)$ & 0.06 \\
\hline Mean $>20 \mathrm{~mm} \mathrm{Hg}, \mathrm{n}(\%)$ & $74(32.7)$ & $31(44.9)$ & \\
\hline
\end{tabular}

Categorical and continuous variables are expressed as the number of patients (\%) and median (IQR), respectively.

${ }^{*}$ Chi-square test for categorical variables and Mann-Whitney U-test for continuous variables.

sisted of admission Glasgow Coma Scale (GCS) score, age, ICP from the 24-hour recording, and dHP. The results were considered significant at $\mathrm{p}<0.05$. All statistical analyses were performed using commercially available software (version 24, IBM SPSS, IBM Corp.; MedCalc Software, version 18.5).

\section{Results \\ Demographics}

The demographics of the 295 TBI patients included in this study (226 surviving, 69 dead) are described in Table 1 . In the total cohort, the median age was 36 years (IQR 23-48 years), the median GCS score was 6 (IQR 3-9), and 222 patients $(75.3 \%)$ were male. There was a significant difference in age and GCS score between the surviving and deceased groups $(p<0.001$ and $p=0.02$, respectively). The number of patients with a mean ICP $>20 \mathrm{~mm} \mathrm{Hg}$ and $>22 \mathrm{~mm} \mathrm{Hg}$ were 105 and 75, respectively.

The mean ABP, ICP, CPP, and PRx showed no statistical significance in differentiating the outcome groups. On the other hand, the duration of hypoperfusion events (denoted as dHP) showed a more effective prognostic capability than the mean values (Table 2, Fig. 2). While the direct comparison of AUCs from dHPs and other integrative parameters (i.e., $\mathrm{PRx}>0.2, \mathrm{CPP}<70 \mathrm{~mm} \mathrm{Hg}$, and $\triangle \mathrm{CPP}$ [optimal CPP - measured CPP] $>5 \mathrm{~mm} \mathrm{Hg}$ ) did not show significance $(\mathrm{p}>0.05)$, the dHP22 exhibited the highest net prediction rate $(\mathrm{dHP} 20=64.56 \%, \mathrm{dHP} 22=$ $65.04 \%$ ). The median dHP of the survival group was 0 minutes, which indicates that events with $\mathrm{PRx}>0.2$, CPP $<70 \mathrm{~mm} \mathrm{Hg}$, and ICP $>22 \mathrm{~mm} \mathrm{Hg}$ rarely occurred in the survival group (Fig. 3).

\section{Prognostic Capability of the Hypoperfusion Index in Patients With a Mean ICP Above $20 \mathrm{~mm} \mathrm{Hg}$}

A significant portion of the patients exhibited sustained intracranial hypertension (Table 1); hence, the prognostic capacity of dHP and other parameters was further investigated for these cohorts (Table 3). Overall, the prognostic capacity of dHP was higher than that of duration of PRx (>0.2), CPP $(<70 \mathrm{~mm} \mathrm{Hg})$, or $\Delta \mathrm{CPP}(>5 \mathrm{~mm} \mathrm{Hg})$. In all conditions, dHP22 exhibited the highest prognostic capacity among the investigated parameters (Fig. 2). The optimal threshold of dHP22 was 24.6 minutes.

The significant prognostic capacity of dHP22 was noted, and a binary logistic regression model was constructed to investigate whether the combined use of basic clinical information that is commonly available during the 1st day of ICP monitoring (i.e., age, admission GCS score, and mean ICP) and dHP22 would be beneficial in predicting mortality (Table 4). Parameters with high collinearity (a variance inflation factor $>10$ ) were not included in the model. All covariates included in the logistic regression had no collinearity (variance inflation factor $<10$ ). When utilized with the basic clinical information, dHP22 yield-

TABLE 2. Prognostic capabilities of the duration of parameters for mortality

\begin{tabular}{|c|c|c|c|c|c|}
\hline & \multicolumn{2}{|c|}{ Median (IQR) in Mins } & \multirow[b]{2}{*}{$\operatorname{AUC}(95 \% \mathrm{Cl})$} & \multirow{2}{*}{$\begin{array}{c}\text { Net Prediction, } \\
\% \\
\end{array}$} & \multirow[b]{2}{*}{ p Value* } \\
\hline & Survived $(n=226)$ & Died $(n=69)$ & & & \\
\hline$P R x>0.2$ & $129.38(50.9-303.54)$ & 218.08 (88.04-533.63) & $0.64(0.56-0.71)$ & 60.23 & $<0.001$ \\
\hline $\mathrm{CPP}<70 \mathrm{~mm} \mathrm{Hg}$ & $141.92(49.12-354.75)$ & $274.17(119.25-464.33)$ & $0.62(0.54-0.69)$ & 61.17 & 0.01 \\
\hline$\Delta \mathrm{CPP}>5 \mathrm{~mm} \mathrm{Hg}$ & $140.55(19.32-280.63)$ & $227.7(54.08-405.77)$ & $0.60(0.52-0.68)$ & 60.17 & 0.05 \\
\hline $\mathrm{dHP} 20$ & $0(0-13.5)$ & $14.33(0-107.17)$ & $0.66(0.58-0.74)$ & 64.56 & $<0.001$ \\
\hline $\mathrm{dHP} 22$ & $0(0-8.37)$ & $6.5(0-68.67)$ & $0.66(0.58-0.74)$ & 65.04 & $<0.001$ \\
\hline
\end{tabular}

${ }^{*}$ Mann-Whitney U-test. 

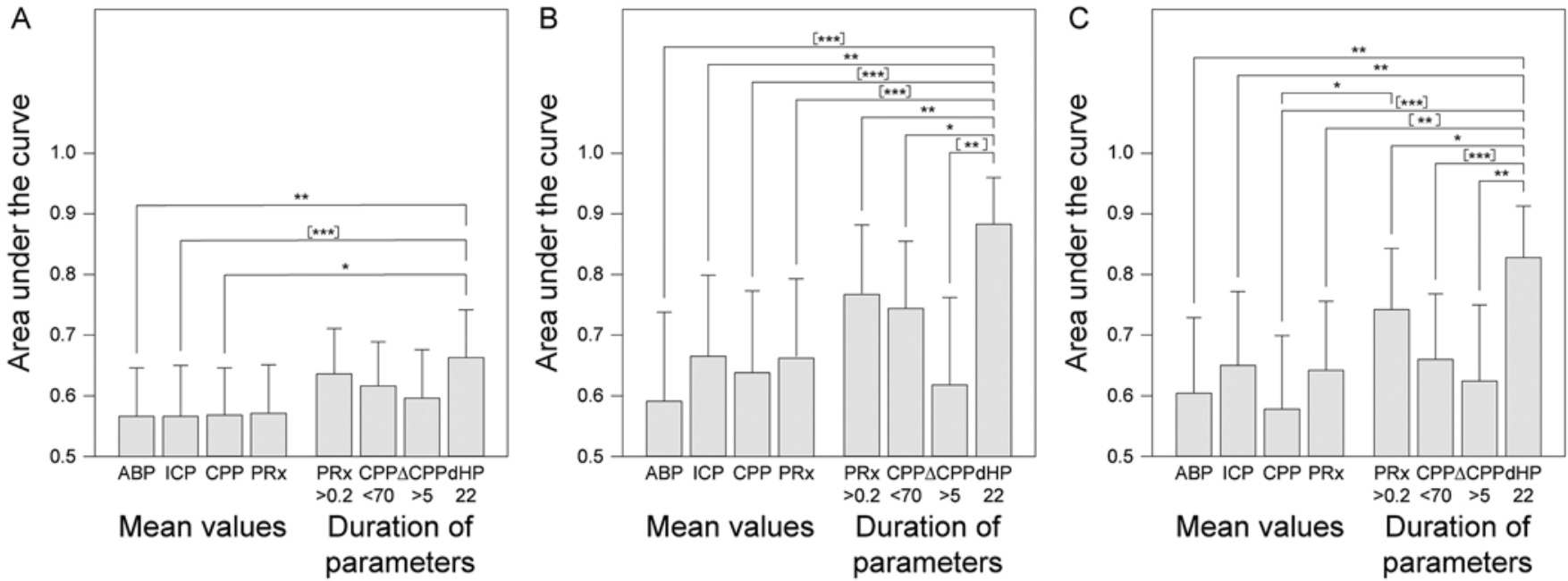

FIG. 2. AUCs predicting mortality for the following conditions: total cohort $(\mathbf{A})$, patients with mean ICP $>22 \mathrm{~mm} \mathrm{Hg}(\mathbf{B})$, and those with ICP $>20 \mathrm{~mm} \mathrm{Hg}(\mathrm{C}) .{ }^{*} p<0.05,{ }^{* *} p<0.01,{ }^{* * *} p<0.001$ by DeLong's method. Brackets denote statistical significance of DeLong's test at $p<0.0017$, which is applied for multiple comparisons by the Bonferroni correction. dHP22 = duration of the severe hypoperfusion event (PRx $>0.2, \mathrm{CPP}<70 \mathrm{~mm} \mathrm{Hg}$, and ICP $>22 \mathrm{~mm} \mathrm{Hg}$ ).

ed an $\mathrm{AUC}=0.75$ for all patients and an AUC over 0.87 if the mean ICP was $>22 \mathrm{~mm} \mathrm{Hg}$ (Table 5).

\section{Discussion}

This study aimed to identify the extent of severe cerebral
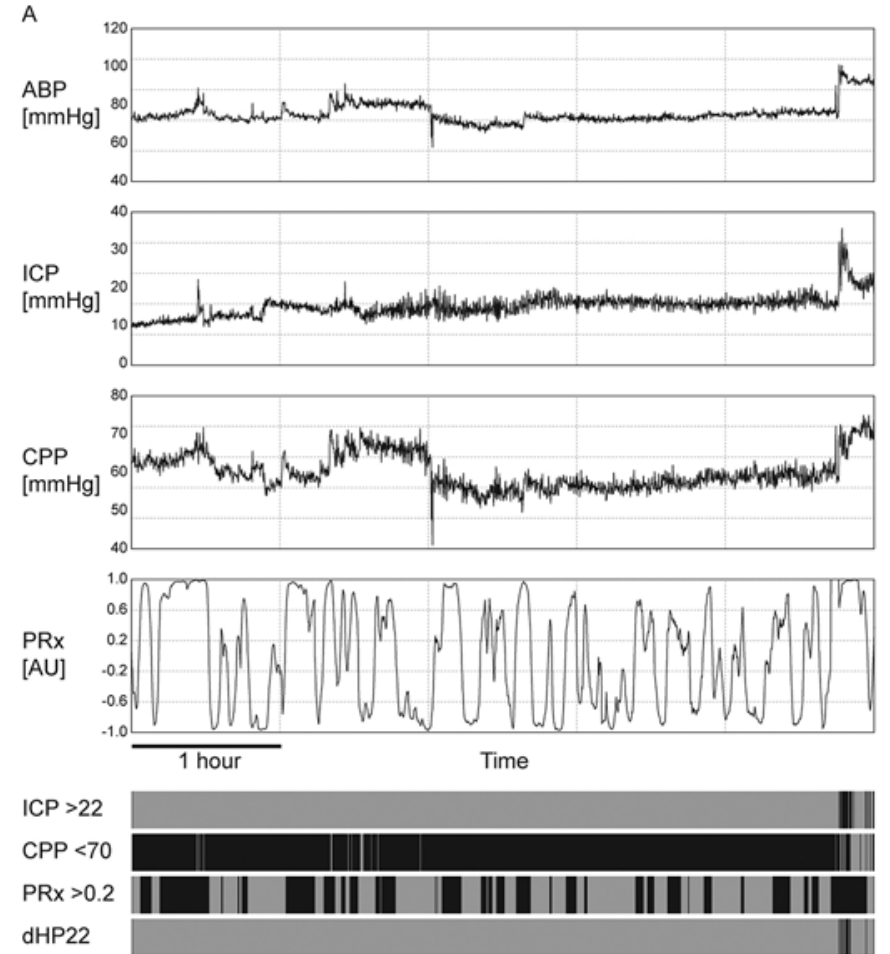

hypoperfusion during the 1st day of ICP monitoring, which has been suggested to be highly predictive of mortality. By measuring the cumulative duration of decreased CPP along with simultaneously increased ICP and worsened cerebrovascular reactivity (evaluated via PRx), the study found that under these circumstances, 1) approximately 25 minutes of
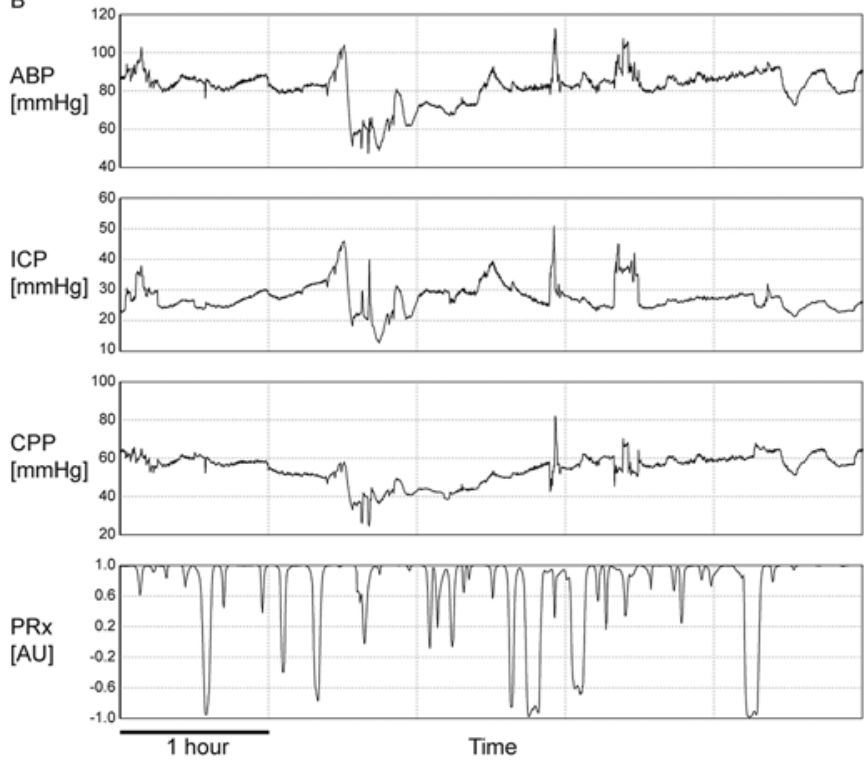

$\mathrm{ICP}>22$

$\mathrm{CPP}<70$

$\mathrm{PRx}>0.2$

dHP22

FIG. 3. Typical examples of dHP monitoring. A: A patient who survived: admission GCS score 13, Glasgow Outcome Scale (GOS) score 4, dHP = 10 minutes. B: A patient who died: admission GCS score 4, GOS score 1, dHP = 989 minutes. Both patients had lowered CPP; however, the patient who survived had intact cerebrovascular reactivity (PRx $<0.2)$ with moderately low ICP and, thus, a short duration of the hypoperfusion event, whereas the deceased patient had high ICP with impaired cerebrovascular reactivity $(P R x>0.2)$, leading to a substantial hypoperfusion event. 
TABLE 3. Prognostic capacities of the parameters for mortality in the patients with mean ICP $>22$ and $>20 \mathrm{mmHg}$

\begin{tabular}{|c|c|c|c|c|c|}
\hline & \multicolumn{2}{|c|}{ Median (IQR) } & \multirow[b]{2}{*}{ AUC $(95 \% \mathrm{Cl})$} & \multirow{2}{*}{$\begin{array}{c}\text { Net } \\
\text { Prediction, \% }\end{array}$} & \multirow{2}{*}{$\underset{\text { Value }^{\mathrm{p}}}{\mathrm{p}}$} \\
\hline & Survived & Died & & & \\
\hline \multicolumn{6}{|l|}{ Mean ICP >22 mm Hg† } \\
\hline \multicolumn{6}{|l|}{ Mean values } \\
\hline $\mathrm{ABP}, \mathrm{mm} \mathrm{Hg}$ & 95.33 (94.12 to 99.1$)$ & 97.54 (94.19 to 101.56$)$ & $0.59(0.44$ to 0.74$)$ & 63.00 & 0.24 \\
\hline ICP, $\mathrm{mm} \mathrm{Hg}$ & 24.42 (23.15 to 27.18$)$ & 26.62 (23.59 to 33.35$)$ & $0.66(0.53$ to 0.8$)$ & 66.00 & 0.02 \\
\hline CPP, $\mathrm{mm} \mathrm{Hg}$ & 70.90 (70.2 to 71.74$)$ & 70.36 (69.48 to 71.02$)$ & 0.64 (0.5 to 0.77$)$ & 63.00 & 0.04 \\
\hline PRx & $-0.10(-0.27$ to 0.06$)$ & $0(-0.12$ to 0.25$)$ & $0.66(0.53$ to 0.79$)$ & 65.00 & 0.04 \\
\hline \multicolumn{6}{|c|}{ Duration of parameters, mins } \\
\hline$P R x>0.2$ & 133.67 (44.31 to 225.77$)$ & 289.33 (141.75 to 736.88$)$ & $0.77(0.65$ to 0.88$)$ & 71.00 & $<0.001$ \\
\hline $\mathrm{CPP}<70 \mathrm{~mm} \mathrm{Hg}$ & 141.92 (80.29 to 331.42$)$ & $326(207.25$ to 551.92$)$ & $0.74(0.63$ to 0.86$)$ & 73.00 & $<0.001$ \\
\hline$\triangle \mathrm{CPP}>5 \mathrm{~mm} \mathrm{Hg}$ & 159.25 (19.32 to 276.65$)$ & 252.48 (81.19 to 452.03$)$ & $0.62(0.47$ to 0.76$)$ & 63.00 & 0.08 \\
\hline $\mathrm{dHP} 20$ & 12.67 (0 to 33.63) & 127.33 (48.67 to 231.58 ) & $0.88(0.8$ to 0.96$)$ & 82.00 & $<0.001$ \\
\hline $\mathrm{dHP} 22$ & 11.17 (0 to 28.63$)$ & 108.5 (40.08 to 204.17 ) & $0.88(0.81$ to 0.96$)$ & 83.00 & $<0.001$ \\
\hline \multicolumn{6}{|l|}{ Mean ICP >20 mm Hg $\ddagger$} \\
\hline \multicolumn{6}{|l|}{ Mean values } \\
\hline $\mathrm{ABP}, \mathrm{mm} \mathrm{Hg}$ & 94.36 (92.33 to 96.59$)$ & 96.51 (93.04 to 100.8$)$ & $0.60(0.48$ to 0.73$)$ & 62.97 & 0.11 \\
\hline ICP, $\mathrm{mm} \mathrm{Hg}$ & 23.17 (21.6 to 26.03$)$ & 26.41 (22.59 to 30.59$)$ & $0.65(0.53$ to 0.77$)$ & 65.00 & 0.02 \\
\hline $\mathrm{CPP}, \mathrm{mm} \mathrm{Hg}$ & 70.61 (70.02 to 71.46$)$ & 70.57 (69.71 to 71.08$)$ & $0.58(0.46$ to 0.70$)$ & 59.92 & 0.18 \\
\hline PRx & $-0.11(-0.27$ to 0.06$)$ & $0(-0.07$ to 0.2$)$ & $0.64(0.53$ to 0.76$)$ & 66.41 & 0.03 \\
\hline \multicolumn{6}{|c|}{ Duration of parameters, mins } \\
\hline$P R x>0.2$ & 128.83 (41.19 to 251.17$)$ & 286.25 (117.25 to 697.58$)$ & $0.74(0.64$ to 0.84$)$ & 67.33 & $<0.001$ \\
\hline $\mathrm{CPP}<70 \mathrm{mmHg}$ & 160.67 (81.75 to 354.75$)$ & 288.17 (194 to 464.83$)$ & $0.66(0.55$ to 0.77$)$ & 67.61 & 0.008 \\
\hline$\Delta \mathrm{CPP}>5 \mathrm{~mm} \mathrm{Hg}$ & 152.32 (21.5 to 274.93$)$ & 252.48 (81.55 to 463.47$)$ & $0.62(0.50$ to 0.75$)$ & 62.45 & 0.04 \\
\hline $\mathrm{dHP} 20$ & 11.58 (0 to 36.54$)$ & 108.5 (35 to 205.83) & $0.81(0.72$ to 0.90$)$ & 76.70 & $<0.001$ \\
\hline $\mathrm{dHP} 22$ & 10.42 (0 to 29.5$)$ & 105.83 (29.67 to 202.5$)$ & $0.83(0.74$ to 0.91$)$ & 78.42 & $<0.001$ \\
\hline
\end{tabular}

${ }^{*}$ Mann-Whitney U-test.

t There were 50 patients who survived and 25 who died.

$\ddagger$ There were 47 patients who survived and 31 who died.

severe hypoperfusion during the 1st day of ICP monitoring was associated with mortality; and 2) a significant proportion of patients who had a high mean ICP ( $>20$ or $>22 \mathrm{~mm}$ $\mathrm{Hg}$ ) was particularly vulnerable to hypoperfusion.

\section{Cerebral Hypoperfusion After TBI}

It is well known that an increased ICP can restrict $\mathrm{CBF} ;{ }^{33}$ however, a decrease in ABP alone may also induce a marked decrease in $\mathrm{CBF}$ in severe TBI patients. ${ }^{16} \mathrm{In}$ fact, hypotension is one of the major systemic complications in TBI, ${ }^{16,22}$ and even a single, short episode of hypotension could double the mortality risk of TBI patients. ${ }^{8}$ Episodes of ABP $<70 \mathrm{~mm} \mathrm{Hg}$ are common in TBI and may contribute $80 \%$ of the CPP reduction during the first few days after TBI (either with or without the increase in ICP). ${ }^{23}$ Furthermore, TBI patients often exhibit failed cerebral autoregulation, especially during the early stage of injury. ${ }^{12}$ Systemic hypotension, intracranial hypertension, and failed cerebral autoregulation can coexist during the acute phase of TBI, leading to the development of severe cerebral hypoperfusion..$^{5,8,15}$

\section{Identifying the "Lethal Dose" of Cerebral Hypoperfusion}

Currently, the PRx remains the most widely validated surrogate measure of cerebral autoregulation. ${ }^{917}$ However, the PRx relies on an important assumption that a change in cerebral blood volume would be reflected as a change in ICP. ${ }^{4}$ Nonetheless, when the pressure-volume relationship is stable (i.e., the pressure-volume curve is flat, e.g., low ICP), the transmission of volume to pressure is weakened. ${ }^{3}$ Thus, the efficacy of the PRx is significantly reduced when ICP is low, due to increased brain compliance. ${ }^{1}$

Instead of attempting to enhance the PRx, this study acknowledged the existing strengths of the PRx; when intracranial compliance is lowered and/or ICP is increased, the PRx would retain its efficacy. Conceptually, the proposed parameter dHP incorporates the event of CPP $<70 \mathrm{~mm}$ $\mathrm{Hg}$ along with $\mathrm{ICP}>20$ (or > 22) $\mathrm{mmHg}$; hence, dHP not only measures intracranial hypertension but also indirectly measures the extent of significant systemic hypotension $(\mathrm{CPP}=\mathrm{ABP}-\mathrm{ICP})$. If cerebrovascular reactivity (hence, cerebral autoregulation) has also failed, the decreased CPP would allow for a decrease in CBF. ${ }^{5,8,15}$ The failure of cerebrovascular reactivity would be estimated by $\mathrm{PRx}>0.2$, provided that the intracranial compliance is low and/or ICP is high. ${ }^{1,3}$

Based on the aforementioned assumptions, we speculated whether the proposed parameter, dHP (defined as the duration of ICP $>20$ or $>22 \mathrm{~mm} \mathrm{Hg}, \mathrm{CPP}<70 \mathrm{~mm} \mathrm{Hg}$, 
TABLE 4. Multivariate logistic regression analysis for predicting mortality

\begin{tabular}{|c|c|c|c|c|}
\hline & OR & $95 \% \mathrm{Cl}$ & $p$ Value & VIF \\
\hline \multicolumn{5}{|l|}{ All patients } \\
\hline ABP & 1.02 & $0.97-1.08$ & 0.36 & 1.31 \\
\hline CPP & 0.98 & $0.92-1.04$ & 0.48 & 1.26 \\
\hline PRx & 1.67 & $0.62-4.46$ & 0.31 & 1.14 \\
\hline Duration of $P R x>0.2$ & 1.00 & $1.00-1.00$ & 0.24 & 1.50 \\
\hline Duration of CPP $<70 \mathrm{~mm} \mathrm{Hg}$ & 1.00 & $1.00-1.00$ & 0.97 & 1.57 \\
\hline Duration of $\Delta \mathrm{CPP}>5 \mathrm{~mm} \mathrm{Hg}$ & 1.00 & $1.00-1.00$ & 0.05 & 1.06 \\
\hline $\mathrm{dHP} 22$ & 1.01 & $1.00-1.01$ & 0.03 & 1.69 \\
\hline \multicolumn{5}{|l|}{ Patients w/ ICP >22 mm Hg } \\
\hline$A B P$ & 1.09 & $0.95-1.25$ & 0.20 & 1.27 \\
\hline CPP & 0.91 & $0.74-1.11$ & 0.35 & 1.12 \\
\hline PRx & 0.91 & $0.10-8.57$ & 0.93 & 1.26 \\
\hline Duration of $\mathrm{PRx}>0.2$ & 1.00 & $1.00-1.00$ & 0.38 & 2.30 \\
\hline Duration of CPP $<70 \mathrm{~mm} \mathrm{Hg}$ & 1.00 & $1.00-1.00$ & 0.86 & 2.43 \\
\hline Duration of $\triangle \mathrm{CPP}>5 \mathrm{~mm} \mathrm{Hg}$ & 1.00 & $1.00-1.01$ & 0.13 & 1.06 \\
\hline $\mathrm{dHP} 22$ & 1.01 & $1.00-1.02$ & 0.04 & 2.67 \\
\hline \multicolumn{5}{|l|}{ Patients w/ ICP >20 mm Hg } \\
\hline$A B P$ & 1.07 & $0.96-1.19$ & 0.22 & 1.27 \\
\hline CPP & 0.92 & $0.75-1.12$ & 0.40 & 1.11 \\
\hline PRx & 1.25 & $0.20-7.73$ & 0.81 & 1.22 \\
\hline Duration of $P R x>0.2$ & 1.00 & $1.00-1.00$ & 0.50 & 2.37 \\
\hline Duration of CPP $<70 \mathrm{~mm} \mathrm{Hg}$ & 1.00 & $1.00-1.00$ & 0.19 & 2.21 \\
\hline Duration of $\triangle \mathrm{CPP}>5 \mathrm{~mm} \mathrm{Hg}$ & 1.00 & $1.00-1.00$ & 0.06 & 1.06 \\
\hline $\mathrm{dHP} 22$ & 1.01 & $1.00-1.03$ & 0.04 & 2.65 \\
\hline
\end{tabular}

$\mathrm{VIF}=$ variance inflation factor.

Odds ratios and their $95 \% \mathrm{Cls}$ were obtained by a multivariate logistic regression analysis with mortality as the dependent variable. Boldface type indicates statistical significance.

and PRx $>0.2$ ), might reflect a decreased CPP during systemic hypotension and failed cerebrovascular reactivity, which would undoubtedly be detrimental to the prognosis of TBI patients. Indeed, the cumulative duration of dHP yielded a moderately high prognostic capacity, despite being obtained for only the first 24 hours of NCCU admission (Table 1). Additionally, a nonnegligible portion of patients exhibited sustained intracranial hypertension, i.e., mean ICP > 20 or $>22 \mathrm{~mm} \mathrm{Hg}(35.6 \%$ and $25.4 \%$, respectively); the cumulative duration of hypoperfusion (evaluated by dHP $>24.6$ minutes) was particularly predictive of outcomes in patients with a mean ICP $>22 \mathrm{~mm} \mathrm{Hg}$, reaching an $82.9 \%$ mortality prediction rate.

The findings of this study indicate that the critical, cumulative duration of such a decrease is approximately 25 minutes. It should be noted that while previous studies have reported the association between outcome and hypoperfusion events, the studies utilized the percentage of time of such events in entire, prolonged recordings. ${ }^{2,13,14,20,21,28,31}$ In practice, one cannot predict how long a patient will be monitored; thus, the generalizability of previous findings in a prospective setting could be quite low. In contrast, dHP provides the cumulative duration of hypoperfusion events; hence, dHP should be better suited for future prospective studies. The proposed parameters deserve more attention, not only for patients with TBI but also for hemorrhagic stroke patients.

\section{Limitations and Suggestions}

Several limitations of this study should be mentioned. The analyzed group of patients has been previously reported on by Aries et al. ${ }^{1,2}$ This is a secondary critical analysis, meaning that alternative indices may be equally as robust as optimal CPP in predicting outcomes. The devised parameter, dHP, is designed to detect severe hypoperfusion events; however, such events would mainly occur via a decrease in ABP. Similarly, due to the purpose of the design, the dHP may not be effective for predicting mortality in patients with hyperperfusion or hyperemia. While effective, the dHP shows greater efficacy when the patient has at least a moderate degree of intracranial hypertension, due to the inherent weakness of the PRx. The utility of dHP in patients without intracranial hypertension should be expected. Another major limitation stems from the use of the specific, predefined thresholds for building dHP, which are yet to be validated as thresholds for identifying hypoperfusion. The proposed parameter is a product of large assumptions, and the findings of this study require further validation in future studies, due to the study's retrospective nature. Recent attempts to overcome the limitations of the PRx and identify patient-specific thresholds of ICP-derived parameters should be reflected in dHP in order for the proposed methods and parameters to be used in a wide variety of clinical situations, preferably with ac-

TABLE 5. Binary logistic regression models to predict mortality

\begin{tabular}{lccc}
\hline & \multicolumn{3}{c}{ OR $(95 \% \mathrm{Cl})$} \\
\cline { 2 - 4 } Variable & All Patients & Mean ICP $>22 \mathrm{~mm} \mathrm{Hg}$ & Mean ICP >20 mm Hg \\
\hline dHP22 & $1.02(1.01-1.02)^{* * *}$ & $1.02(1.01-1.03)^{* *}$ & $1.01(1.01-1.02)^{* *}$ \\
\hline Age & $1.028(1.01-1.05)^{* *}$ & $1.056(1.01-1.10)^{*}$ & $1.03(1.00-1.06)$ \\
\hline GCS & $0.846(0.77-0.93)^{* * *}$ & $0.891(0.73-1.09)$ & $0.93(0.80-1.08)$ \\
\hline ICP & $0.919(0.88-0.96)^{* * *}$ & $0.886(0.82-0.96)^{* *}$ & $0.92(0.86-0.98)^{* *}$ \\
\hline Log likelihood & -123.19 & -25.10 & -43.47 \\
\hline Akaike information criterion & 254.38 & 58.20 & 94.94 \\
\hline AUC & $0.75(0.68-0.82)$ & $0.87(0.76-0.98)$ & $0.81(0.71-0.91)$ \\
\hline${ }^{*} \mathrm{p}<0.05,{ }^{* *} \mathrm{p}<0.01,{ }^{* * *} \mathrm{p}<0.001$. & & &
\end{tabular}


tual measurements of CBF. In particular, the prognostic capacity of dHP was higher when constructed with the recent ICP threshold of $22 \mathrm{~mm} \mathrm{Hg}$ than when constructed with the conventional ICP threshold of $20 \mathrm{~mm} \mathrm{Hg}$; future studies may benefit from utilizing the recent ICP threshold when conducting ICP monitoring-derived signal analyses.

\section{Conclusions}

This study measured the extent of severe hypoperfusion in TBI patients during the first 24 hours of NCCU admission with the combined use of ICP, CPP, and the status of cerebrovascular reactivity. A total time of approximately 25 cumulative minutes of hypoperfusion was highly predictive of mortality, especially for patients whose mean ICP was $>20$ or $>22 \mathrm{~mm} \mathrm{Hg}$.

\section{Acknowledgments}

This research was supported by a grant from the Korea Health Technology R\&D Project through the Korea Health Industry Development Institute (KHIDI), funded by the Ministry of Health \& Welfare, Republic of Korea (grant no. HI17C1790); the MSIT (Ministry of Science and ICT), Korea, under the ITRC (Information Technology Research Center) support program (IITP-20182016-0-00464) supervised by the IITP (Institute for Information \& communications Technology Promotion); an IITP grant funded by the Korea government (MSIT) (no. 2017-0-00432, Development of non-invasive integrated BCI SW platform to control home appliances and external devices by user's thought via AR/ VR interface); a Korea University Grant. M.C. was supported by NIHR Brain Research Centre, Cambridge.

We sincerely thank all staff at the Neurocritical Care Unit in Addenbrookes Hospital, Cambridge, United Kingdom, for their support and professional help with the computer pressure recordings of TBI patients.

\section{References}

1. Aries MJ, Czosnyka M, Budohoski KP, Kolias AG, Radolovich DK, Lavinio A, et al: Continuous monitoring of cerebrovascular reactivity using pulse waveform of intracranial pressure. Neurocrit Care 17:67-76, 2012

2. Aries MJ, Czosnyka M, Budohoski KP, Steiner LA, Lavinio A, Kolias AG, et al: Continuous determination of optimal cerebral perfusion pressure in traumatic brain injury. Crit Care Med 40:2456-2463, 2012

3. Avezaat CJ, van Eijndhoven JH, Wyper DJ: Cerebrospinal fluid pulse pressure and intracranial volume-pressure relationships. J Neurol Neurosurg Psychiatry 42:687-700, 1979

4. Bouma GJ, Muizelaar JP, Bandoh K, Marmarou A: Blood pressure and intracranial pressure-volume dynamics in severe head injury: relationship with cerebral blood flow. J Neurosurg 77:15-19, 1992

5. Bouzat P, Marques-Vidal P, Zerlauth JB, Sala N, Suys T, Schoettker P, et al: Accuracy of brain multimodal monitoring to detect cerebral hypoperfusion after traumatic brain injury. Crit Care Med 43:445-452, 2015

6. Bouzat P, Sala N, Payen JF, Oddo M: Beyond intracranial pressure: optimization of cerebral blood flow, oxygen, and substrate delivery after traumatic brain injury. Ann Intensive Care 3:23, 2013

7. Carney N, Totten AM, O'Reilly C, Ullman JS, Hawryluk $\mathrm{GW}$, Bell MJ, et al: Guidelines for the management of severe traumatic brain injury fourth edition. Neurosurgery 80:615,2017
8. Chesnut RM, Marshall LF, Klauber MR, Blunt BA, Baldwin $\mathrm{N}$, Eisenberg HM, et al: The role of secondary brain injury in determining outcome from severe head injury. J Trauma 34:216-222, 1993

9. Czosnyka M, Czosnyka Z, Smielewski P: Pressure reactivity index: journey through the past 20 years. Acta Neurochir (Wien) 159:2063-2065, 2017

10. Czosnyka M, Smielewski P, Kirkpatrick P, Laing RJ, Menon D, Pickard JD: Continuous assessment of the cerebral vasomotor reactivity in head injury. Neurosurgery 41:11-19, 1997

11. DeLong ER, DeLong DM, Clarke-Pearson DL: Comparing the areas under two or more correlated receiver operating characteristic curves: a nonparametric approach. Biometrics 44:837-845, 1988

12. DeWitt DS, Prough DS: Molecular and cellular mechanisms of traumatic cerebral vascular injury, in Clark RSB, Kochanek P (eds): Brain Injury. Boston: Springer, 2001, pp 71-97

13. Diedler J, Santos E, Poli S, Sykora M: Optimal cerebral perfusion pressure in patients with intracerebral hemorrhage: an observational case series. Crit Care 18:R51, 2014

14. Donnelly J, Czosnyka M, Adams H, Robba C, Steiner LA, Cardim D, et al: Individualizing thresholds of cerebral perfusion pressure using estimated limits of autoregulation. Crit Care Med 45:1464-1471, 2017

15. Faraci FM, Heistad DD: Regulation of large cerebral arteries and cerebral microvascular pressure. Circ Res 66:8-17, 1990

16. Gobiet W, Grote W, Bock WJ: The relation between intracranial pressure, mean arterial pressure and cerebral blood flow in patients with severe head injury. Acta Neurochir (Wien) 32:13-24, 1975

17. Highton D, Ghosh A, Tachtsidis I, Panovska-Griffiths J, Elwell CE, Smith M: Monitoring cerebral autoregulation after brain injury: multimodal assessment of cerebral slow-wave oscillations using near-infrared spectroscopy. Anesth Analg 121:198-205, 2015

18. Lang EW, Kasprowicz M, Smielewski P, Santos E, Pickard J, Czosnyka M: Short pressure reactivity index versus long pressure reactivity index in the management of traumatic brain injury. J Neurosurg 122:588-594, 2015

19. Lazaridis C, DeSantis SM, Smielewski P, Menon DK, Hutchinson P, Pickard JD, et al: Patient-specific thresholds of intracranial pressure in severe traumatic brain injury. $\mathbf{J}$ Neurosurg 120:893-900, 2014

20. Lazaridis C, Smielewski P, Steiner LA, Brady KM, Hutchinson P, Pickard JD, et al: Optimal cerebral perfusion pressure: are we ready for it? Neurol Res 35:138-148, 2013

21. Liu X, Donnelly J, Czosnyka M, Aries MJH, Brady K, Cardim D, et al: Cerebrovascular pressure reactivity monitoring using wavelet analysis in traumatic brain injury patients: a retrospective study. PLoS Med 14:e1002348, 2017

22. Mahoney EJ, Biffl WL, Harrington DT, Cioffi WG: Isolated brain injury as a cause of hypotension in the blunt trauma patient. J Trauma 55:1065-1069, 2003

23. Marmarou A, Saad A, Aygok G, Rigsbee M: Contribution of raised ICP and hypotension to CPP reduction in severe brain injury: correlation to outcome. Acta Neurochir Suppl 95:277-280, 2005

24. Patel HC, Menon DK, Tebbs S, Hawker R, Hutchinson PJ, Kirkpatrick PJ: Specialist neurocritical care and outcome from head injury. Intensive Care Med 28:547-553, 2002

25. Paulson OB, Strandgaard S, Edvinsson L: Cerebral autoregulation. Cerebrovasc Brain Metab Rev 2:161-192, 1990

26. Radolovich DK, Aries MJ, Castellani G, Corona A, Lavinio A, Smielewski P, et al: Pulsatile intracranial pressure and cerebral autoregulation after traumatic brain injury. Neurocrit Care 15:379-386, 2011

27. Rangel-Castilla L, Gopinath S, Robertson CS: Management of intracranial hypertension. Neurol Clin 26:521-541, x, 2008 (Erratum in Neurol Clin 26:xvii, 2008) 
28. Rasulo FA, Girardini A, Lavinio A, De Peri E, Stefini R, Cenzato M, et al: Are optimal cerebral perfusion pressure and cerebrovascular autoregulation related to long-term outcome in patients with aneurysmal subarachnoid hemorrhage? J Neurosurg Anesthesiol 24:3-8, 2012

29. Rosner MJ, Rosner SD, Johnson AH: Cerebral perfusion pressure: management protocol and clinical results. J Neurosurg 83:949-962, 1995

30. Steiner LA, Coles JP, Johnston AJ, Chatfield DA, Smielewski P, Fryer TD, et al: Assessment of cerebrovascular autoregulation in head-injured patients: a validation study. Stroke 34:2404-2409, 2003

31. Steiner LA, Czosnyka M, Piechnik SK, Smielewski P, Chatfield D, Menon DK, et al: Continuous monitoring of cerebrovascular pressure reactivity allows determination of optimal cerebral perfusion pressure in patients with traumatic brain injury. Crit Care Med 30:733-738, 2002

32. Sykora M, Czosnyka M, Liu X, Donnelly J, Nasr N, Diedler $\mathrm{J}$, et al: Autonomic impairment in severe traumatic brain injury: a multimodal neuromonitoring study. Crit Care Med 44:1173-1181, 2016

33. Tameem A, Krovvidi H: Cerebral physiology. Contin Educ Anaesth Crit Care Pain 13:113-118, 2013

34. Vigué B, Ract C, Tazarourte K: The first 24 hours after severe head trauma, in Vincent JL (ed): Annual Update in Intensive Care and Emergency Medicine 2012. Berlin: Springer, 2012, pp 722-731
35. Werner C, Engelhard K: Pathophysiology of traumatic brain injury. Br J Anaesth 99:4-9, 2007

36. Zweifel C, Lavinio A, Steiner LA, Radolovich D, Smielewski P, Timofeev I, et al: Continuous monitoring of cerebrovascular pressure reactivity in patients with head injury. Neurosurg Focus 25(4):E2, 2008

\section{Disclosures}

ICM+, a signal processing software used in this study, is licensed through Cambridge Enterprise Ltd., Cambridge, UK. M. Czosnyka has a financial interest in $10 \%$ of the licensing fee, and $\mathrm{P}$. Smielewski receives part of licensing fees.

\section{Author Contributions}

Conception and design: DJ Kim, H Kim. Acquisition of data: P Smielewski, M Czosnyka. Analysis and interpretation of data: DJ Kim, H Kim, HJ Lee, YT Kim, Y Son. Drafting the article: H Kim. Critically revising the article: all authors. Reviewed submitted version of manuscript: all authors. Approved the final version of the manuscript on behalf of all authors: DJ Kim. Statistical analysis: YT Kim. Study supervision: DJ Kim.

\section{Correspondence}

Dong-Joo Kim: Korea University, Seoul, South Korea. dongjookim@korea.ac.kr. 